\title{
DIREITO E ESTADO SOB A PERSPECTIVA DA SOCIEDADE DA INFORMAÇÃO
}

\section{Maria Fernanda Stocco Ottoboni *}

\section{Resumo}

O presente artigo, a partir da metodologia qualitativa, método analítico e pesquisa bibliográfica, objetiva a análise da sociedade da informação, sua relação com as novas tecnologias e sua influência na compreensão de Direito e Estado em perspectiva contemporânea. Para tanto, o estudo inicia com reflexões, a fim da contextualização sobre a sociedade da informação. Por conseguinte, passa à abordagem sobre o Direito e, após, do Estado, na sociedade da informação, analisando de que forma o processo de transformação, de evolução e de disrupção impactam esses conceitos. Ao final, contempla breve reflexão sob o Direito e o Estado em perspectiva contemporânea.

Palavras-chave: Novas tecnologias; Disrupção; Sociedade da Informação; Direito; Estado.

\section{LAW AND STATE FROM THE PERSPECTIVE OF THE INFORMATION SOCIETY}

\begin{abstract}
This article, based on qualitative methodology, analytical method and bibliographic research, aims to analyze the information society, its relationship with new technologies and its influence on the understanding of Law and State in a contemporary perspective. To this end, the study begins with reflections, in order to contextualize the information society. Consequently, it moves to the approach on Law and, later, on the State, in the information society, analyzing how the process of transformation, evolution and disruption impact these concepts. At the end, it contemplates a brief reflection on the Law and the State in a contemporary perspective.
\end{abstract}

Key words: New Technologies; Disruption; Information Society; Law; State.

\section{INTRODUÇÃO}

Após a segunda-guerra mundial, inúmeros avanços na esfera social e, por conseguinte, na jurídica (uma vez que o Direito regula as atividades a ela inerentes), se propagaram, principalmente no que concerne, inicialmente, às inovações industriais e,

\footnotetext{
* Advogada desde 2011 (OAB/SP 310.624). Mestranda no Programa de Pós-Graduação Stricto Sensu em Direito, do Centro Universitário Eurípides de Marília - UNIVEM, com área de concentração em Direito e Estado na Era Digital e linha de pesquisa em Acesso à Justiça e Inovação Tecnológica. Mediadora e conciliadora no Centro de Soluções de Conflitos e Cidadania - CEJUSC do Tribunal de Justiça do Estado de São Paulo, da Comarca de Marília-SP (2014-2017). Especialista em Direito Processual Civil pela Pontifícia Universidade Católica de São Paulo (2010-2012). Graduação em Direito pela Universidade Presbiteriana Mackenzie (2005-2010). mariafernanda.ottoboni@gmail.com.
} 
posteriormente, às inovações tecnológicas, estas últimas marcando o período pós-industrial, também comumente designado pós-modernismo ou pós-modernidade e que se estende à contemporaneidade.

O referido período histórico é marcado pela quarta revolução industrial, que de forma bastante resumida, se demonstra por meio de um processo contemporâneo de mudanças importantes nas tendências artísticas, filosóficas, sociológicas e científicas, vindo acompanhado das inovações tecnológicas, da expansão dos meios de comunicações, do sistema capitalista e da globalização.

Dessa maneira, é inegável que a sociedade contemporânea vivencia um processo de transformação, de evolução e de disrupção, marcada pela convergência de tecnologias digitais, físicas e biológicas. Vivencia-se, de forma cada vez mais acelerada, uma sociedade da informação e do conhecimento, no contexto da qual a inteligência artificial, a robótica, diferentes tecnologias da informação e comunicação, a realidade aumentada, o big-data e a internet das coisas, por exemplo, vem assumindo papel primordial implicando profundas alterações na sociedade e também no âmbito político e econômico.

É de se compreender, então, que a sociedade da informação do século XXI vem substituir a sociedade industrial do século XX, provocando mudanças no cotidiano das pessoas, na vida em sociedade e, assim, refletindo diretamente nos conceitos de Direito e Estado.

O presente artigo, portanto, enfrenta os temas propostos por meio de uma abordagem qualitativa de metodologia, utilizando-se do método analítico, através de pesquisa bibliográfica, intentando contribuir com reflexões sobre Direito e Estado em perspectiva contemporânea, analisando-os no contexto da chamada sociedade da informação e das inovações tecnológicas a fim de descobrir quais os impactos e consequências desse movimento contemporâneo.

\section{A SOCIEDADE DA INFORMAÇÃO}

Na contemporaneidade são verificadas, cada vez mais, mudanças rápidas e contínuas na sociedade, as quais são impulsionadas, principalmente, pelo avanço tecnológico. Tal fenômeno tem sido denominado de revolução da informação, a partir do qual emergiram conceitos como era da informação, sociedade da informação ou a sociedade em rede, 
conforme discorre Castells (2002).

Em relação a esse fenômeno, o referido autor acima mencionado, discorre que:

No fim do segundo milênio da Era Cristã, vários acontecimentos de importância histórica transformaram o cenário social da vida humana. Uma revolução tecnológica concentrada nas tecnologias da informação começou a remodelar a base material da sociedade em ritmo acelerado (CASTELLS, 2002, p. 39).

A revolução tecnológica vivenciada desde à época acima retratada e que de forma cada vez mais intensa se verifica nos dias hodiernos a partir da disseminação das inovações, rompe com o padrão até então existente nas inúmeras maneiras e âmbitos de convivência e relacionamentos em sociedade, impactando, com isso, o próprio Estado, com reflexos diretos na economia, política e, também, no Direito.

Nesse passo, Lastres e Albagli (1999, p. 8) constatam, portanto, que tais inovações constituem-se em elementos de ruptura (para alguns), ou de forte diferenciação (para outros), em relação ao padrão precedente, ainda que resultantes, em grande medida, de tendência e vetores que não são propriamente novos ou recentes.

A sociedade contemporânea é, reconhecidamente, a sociedade da informação. E nesse contexto, contribui Rodrigo da Cunha Lima Freire com a seguinte reflexão para a sua constatação a esse respeito:

Nas últimas décadas o mundo vem experimentando notáveis transformações em função da aceleração dos mecanismos de difusão das informações, proporcionada, especialmente, pelo desenvolvimento tecnológico das telecomunicações e da microeletrônica. A facilitação do acesso à informação pelo diversos meios de comunicação, como o rádio, a televisão, os telefones e os computadores - especialmente com o advento de novas tecnologias como a internet, o satélite, a telefonia celular e a rede de fibra óptica mundial -, modificou - e vem modificando - substancialmente as relações sociais, econômicas e jurídicas, razão pela qual se pode dizer, que a sociedade contemporânea é da informação (FREIRE, 2006, p. 247).

Roberto Senise Lisboa, analisando de forma comparativa os períodos históricos marcados pela revolução industrial, anteriormente, e pela revolução informacional, atualmente, discorre que:

Enquanto a revolução industrial objetivava o desenvolvimento da produção de bens tangíveis ou corpóreos, coube à revolução da informação a finalidade de desenvolver as tecnologias de produção, por meio do acúmulo do conhecimento e da facilitação de seu acesso a todas as pessoas. A revolução informacional cuida, pois, do acesso aos bens intangíveis ou incorpóreos. E como, por meio deles, se torna possível o acesso aos bens 
tangíveis e corpóreos (LISBOA, 2006, p. 85).

A fim de complementar o entendimento acerca da sociedade da informação e seus impactos a tudo e a todos, João Antonio Zuffo, por seu turno, discorre que:

\begin{abstract}
A Infoera, a era da informação e do conhecimento, está crescentemente se impondo na estrutura social mundial, atingindo os mais recônditos lugares de nosso planeta. A imensa revolução da informática, traduzida pela evolução tecnológica das metodologias de produção na microeletrônica, assim como pela evolução tecnológica do processamento de dados e do processamento de informações e, finalmente, pela evolução tecnológica das telecomunicações propriamente ditas, está agora se espraiando, propagandose e disseminando-se para todos os demais setores das atividades socioeconômicas. Nesse afã difusivo, independentemente das flutuações econômicas, está contaminando, com seu ritmo alucinante, turbulento e febril, todas as organizações, todas as associações e, enfim, todos os seres humanos (ZUFFO, 2003, p. 17-18).
\end{abstract}

A informação é, portanto, o novo paradigma da sociedade. Cuida-se de uma peça fundamental da contemporaneidade, mas que não se mostra pronta e disponível isoladamente. É necessário compreenda-la e entendê-la, estando intrinsecamente ligada ao conhecimento.

Nesse contexto, como conceito de informação, Maria Eduarda Gonçalves apresenta que:

O conceito de informação implica, em rigor, um estado de consciência sobre os factos ou dados; o que quer dizer que pressupõe um esforço (de carácter intelectual, antes de mais) que permita passar da informação imanente (dos factos ou dos dados brutos) à sua percepção e entendimento, o que implica, normalmente, a sua recolha, tratamento e organização (GONÇALVES, 2003, p. 17).

Diante desse contexto, para Stewart (2002, p. 31-35), dados e informações são menos importantes do que conhecimento. Conhecimento não é soma, é agregação, interação, acumulação. Os dados e as informações conectam-se entre si para formar o conhecimento. $\mathrm{O}$ conhecimento envolve expertise. Para alcançá-lo é preciso tempo. Dura mais do que a informação e por vezes é eterno. Conhecimento, enfim, é o que fazemos. Dessa maneira, considera que desde as formas de conhecimento e de obtenção de informações e dados mais rudimentares até as mais sofisticadas por força do implemento da tecnologia, percebe-se a valorização que se dá, especialmente nesse início de século, à informação.

Outro conceito da sociedade da informação que merece destaque, uma vez que se mostra complementar ao quanto acima exposto, é o que considera que: 
Sociedade da informação", também denominada de "sociedade do conhecimento", é expressão utilizada para identificar o período histórico a partir da preponderância da informação sobre os meios de produção e a distribuição dos bens na sociedade que se estabeleceu a partir da vulgarização das programações de dados utiliza dos meios de comunicação existentes e dos dados obtidos sobre uma pessoa e/ou objeto, para a realização de atos e negócios jurídicos (LISBOA, 2006, p.8-9).

É crível, portanto, que a sociedade da informação tem como principal valor a informação e o conhecimento. Contudo, cumpre ressaltar que a informação não é, por si só, a grande novidade do período contemporâneo. Na verdade, o ponto principal desta nova era é a velocidade e quantidade da informação, as quais evoluíram e evoluem a cada dia e cada vez mais em proporções nunca antes imaginadas.

Essa rapidez com que as tecnologias se expandiram e adentraram abruptamente no cotidiano foram trazendo inúmeros progressos. O desenvolvimento das tecnologias de informação e a expansão das redes de computadores proporcionaram não apenas uma maior velocidade e dinamismo às comunicações e relações entre os indivíduos e agrupamentos humanos, abrindo novos e largos horizontes de uso, como também teve importantes implicações na mobilidade dos fluxos econômicos, nas relações humanas, na produção de conhecimento, no trabalho e na produtividade, nas relações dos indivíduos com os organismos públicos, nas relações entre os Estados, entres outros aspectos (MACHADO, 2003, p. 9-10).

Dentre as inovações tecnológicas constatadas no período contemporâneo, é possível destacar que os algoritmos e a inteligência artificial podem ser utilizados de forma benéfica e positiva à sociedade.

É nessa tendência que Paulo Sá Elias aposta. Contudo, contemporiza toda essa empolgação e benefícios que as tecnologias e a sociedade da informação trazem consigo, alertando que há necessidade de constante vigia:

Há um grande potencial para que os algoritmos e a inteligência artificial possam ser usados para o bem de toda a sociedade. Na verdade, há uma oportunidade para tornar o mundo mais justo e menos tendencioso com a utilização dos algoritmos e da inteligência artificial. As leis não devem travar e dificultar a inovação, mas, reitera-se, não podemos ser ingênuos e deslumbrados com as novas tecnologias, deixando de perceber o que está por trás de tudo isso (ELIAS, 2021).

Assim, em que pese esse lado positivo de muitos avanços trazidos com essa sociedade da informação, Gilberto Dupas apresenta, em linhas de ressalva, contraponto interessante a ser refletido e observado em meio a tantos avanços: 
Durante o século XX, o capitalismo global apossou-se por completo dos destinos da tecnologia, libertando-a de amarras metafísicas e orientando-a única e exclusivamente para a criação de valor econômico. Transformados em fator fundamental na disputa dos mercados e na acumulação capitalista global, os vetores tecnológicos autonomizaram-se definitivamente de considerações de natureza ética, social ou de políticas públicas. As conseqüências foram, dentre outras, o aumento da concentração de renda e da exclusão social, o perigo de destruição do habitat humano por contaminação e a manipulação genética, ameaçando o patrimônio comum da humanidade. É preciso pois buscar condições para que nova hegemonia mundial, que inclua mas não se constranja ao capital, possa construir um mundo melhor, utilizando-se dos avanços da ciência em benefício da grande maioria de seus cidadãos (DUPAS, 2001, p. 117-122).

Diante das mudanças profundas provocadas nas relações sociais, a sociedade da informação impõe-se como realidade complexa a qual impacta a tudo e a todos.

A vivência dessa nova realidade é atual e por isso requer que os cidadãos e os profissionais de todas as áreas se atualizem e se reinventem, na busca incessante de, sobretudo, compreendê-la, abrindo seus horizontes de forma a se adaptarem ao campo de atuação em constante e rápida expansão.

Mas, é importante que tudo isso seja realizado com constante vigia, prezando por condutas adequadas, a fim de que os avanços busquem beneficiar cada vez mais a maioria da sociedade, e não o contrário, cuidando para que não prevaleça e que não propicie desigualdades e que fique marcada por um cenário de exclusão.

Nesse sentido, Araújo (1994) atenta que para além do discurso de que informação é poder, é importante a conscientização do poder transformador de "fazer, agir e construir" da informação por sua poderosa força transformadora. [...] o poder da informação, aliado aos modernos meios de comunicação de massa, tem capacidade ilimitada de transformar culturalmente o homem, a sociedade e a própria humanidade como um todo (ARAÚJO, 1994, p. 84).

E é exatamente nesse contexto dessa nova realidade social que impacta as relações socioeconômicas e reflete, inclusive, na compreensão e no papel do Estado, que cada vez mais se exige que o operador do direito seja capaz de enfrentar os comportamentos almejados socialmente, sobretudo na perspectiva de uma conduta ética e apropriada, distante da tradicional visão do direito como ameaça, pena e coação em geral.

Dessa maneira, conforme defende Siqueira Júnior (2007, p. 13), sem descuidar de sua formação técnica, os profissionais da área jurídica precisam, assim como todos os 
profissionais de tantas outras áreas, abrir seus horizontes para um contexto científico e social ampliado, no qual deverá agir, sendo fundamental, porém, que não perca de vista o problema da exclusão, tornado mais e mais agudo pela complexidade social.

\section{O DIREITO NA SOCIEDADE DA INFORMAÇÃO}

Como abordado nas linhas alhures, a informação é, portanto, o elemento central da sociedade contemporânea, sendo, por conseguinte, em torno dela que as relações sociais, econômicas e políticas são pautadas. A informação trata-se, em decorrência desse seu papel de destaque, de elemento propulsor da riqueza na sociedade atual.

Na sociedade contemporânea, o conhecimento e a comunicação se tornaram fatores centrais tanto na vida pública quanto privada, pois é a partir deles que o elemento central, a informação, compreendido e propagado, produzindo seus efeitos no contexto social.

Dessa maneira, a informação é tema que permeia e impacta diretamente o estudo no Direito, e isto em seus âmbitos tanto público, como privado.

No aspecto público do Direito, são comuns as situações jurídicas girarem em torno dos temas de cidadania digital e de acesso à informação. No Direito sob seu aspecto privado, é a proteção da intimidade que ganha novos contornos e permeia as preocupações nesse contexto da sociedade da informação.

A sociedade da informação é marcada por um contexto de globalização. A transnacionalização e a formação de novos blocos sócio-econômicos, além da interdependência das esferas produtivas e financeiras e os mecanismos alternativos/adequados de resolução de conflitos, oriundos desse novo contexto sociail, abalaram o pensamento jurídico construído em torno de conceitos e princípios característicos da modernidade, tais como soberania, legalidade, direito subjetivo, território, segurança e cidadania, por exemplo.

Assim, visando a adequação a essa nova realidade imposta com o advento da sociedade da informação, surgiu o direito informacional, cujo objeto de estudo são justamente os novos direitos emergentes desse mundo contemporâneo e globalizado.

O chamado direito informacional caracteriza-se por um conjunto de institutos jurídicos que visam tutelar a informação. Sobre este aspecto, Gonçalves (2003, p. 23) discorre que se trata de um conjunto de temas de direito que convergem num tronco comum: a informação 
como um recurso central da economia e da sociedade.

Referida autora confere ainda a seguinte explicação acerca do chamado direito informacional:

[...] o Direito da Informação agrupará, assim, as normas e princípios jurídicos cujo objecto são as relações jurídicas geradas em torno da utilização das novas tecnologias da informação e da comunicação para a recolha, o processamento e/ou a transmissão da informação. Os domínios cobertos são potencialmente vastos: eles estendem-se dos regimes da propriedade intelectual sobre programas de computador (meios de tratamento da informação), bases de dados ou produtos multimídia (informação propriamente dita) ou de um modo mais geral as criações intelectuais produzidas em redes como a internet, aos regimes aplicáveis a recolha, utilização e circulação de diferentes categorias de informação (pessoal, administrativa ou outras); e envolverão ainda o quadro regulador da comunicação nas redes globais (GONÇALVES, 2003, p. 21).

Siqueira Júnior (2007, p. 13) elenca três características que considera serem destaque nesse âmbito do estudo do Direito intimamente relacionado à sociedade da informação. A primeira delas é o fim da dicotomia entre o direito público e o direito privado, pois o direito informacional vale-se de institutos dos dois ramos tradicionais do direito; a segunda, a verificação de instrumentos de auto-regulação, com a redução da atuação jurisdicional do Estado e, por fim, a terceira, o aumento da tutela coletiva, ante a sociedade massificada da informação.

Dessa maneira, os impactos da sociedade da informação na compreensão e na operação do Direito são latentes.

Roberto Senise Lisboa, com brilhante clareza, elucida que:

A informática transformou o mundo, porém a sua revolução não suprimiu o que se havia feito no passado: os sistemas de produção de bens não se encontram apenas mecanizados, como também eletronizados, e por programas de dados; a grande maioria dos negócios jurídicos são realizados mediante o processo de computação, ainda que não celebrados pela via virtual; os sistemas de transporte submetem-se a programas de dados para o funcionamento dos coletivos (como sucede, por exemplo, com o metrô); a biotecnologia se utiliza de processos novos para o diagnóstico e o tratamento de doenças; o controle dos poluentes passa a ter um eficaz aliado a partir da utilização do programa de dados. Ou seja: a Sociedade da Informação veio aprimorar o convívio social, colaborando para o progresso e facilitando o acesso à informação, inclusive para os fins de celebração do ato e do negócio jurídico. Logo, todos os ramos do direito devem ser revisitados à luz da Sociedade da Informação: o Direito Civil, o Direito Empresarial, o Direito do Consumidor, o Direito Processual, o Direito do Trabalho, o Direito 
Tributário, o Direito Administrativo, etc (LISBOA, 2006, p. 13).

A evolução das tecnologias é, portanto, contínua e se dá cada vez de forma mais célere. Atualmente, questões como o avanço no processamento e armazenamento de dados e a proteção dos direitos dos titulares desses dados são o foco de destaque do Direito, em suas diversas áreas. Esse contexto, portanto, exige dos operadores do Direito uma nova visão, no sentido de compreender e encontrar mecanismos adequados de regulação, controle e resolução de conflitos relacionados a esses diretos emergentes da sociedade da informação.

Nesse contexto, interessante se faz mencionar Paulo Hamilton Siqueira Júnior que, de forma bastante clara e precisa elucida que:

O direito informacional é dinâmico, pois para acompanhar a evolução rápida e contínua da sociedade atual, urge a necessidade de revisão de paradigmas, em especial aquele que define o direito como o conjunto de regras positivadas pelo Estado. Essa sociedade exige outras fontes do direito para a resolução dos conflitos sociais, incluindo aí as não-estatais.

Daí o direito não se resume ao fato social normativo, mas incluem também a dinâmica da sociedade, sendo que as normas e os princípios jurídicos tornam balizas jurídicas para resolver os casos concretos. O direito informacional exige do operador do direito não a postura de um simples aplicador da norma ao caso concreto, mas uma postura criativa. Sob o plano políticoconstitucional é relativizada a tendência de se apresentar o Estado como fonte exclusiva do direito (SIQUEIRA JÚNIOR, 2007, p. 167-168).

Portanto, o Direito, na contemporaneidade, necessariamente é impactado pela realidade social atual, exigindo uma releitura dos institutos jurídicos, dos conceitos até então tidos como tradicionais. Uma vez que as relações mantidas no âmbito social ganham novos contornos a cada dia, o Direito, como reflexo direto, deve adaptar-se e modificar-se visando contemporizar e tutelar os direitos oriundos desse novo contexto, tornando-se, por seu turno, ainda mais complexo.

Dessa maneira, do operador do direito é exigido um constante esforço em busca do conhecimento e de um readaptar-se de acordo com as novas demandas e exigências do mercado e da sociedade. É por tudo isso que a sociedade da informação impacta diretamente, também, a formação dos operadores do Direito. Assim, a educação jurídica também merece ser revisitada, visando adaptação e adequação a essa nova realidade, a fim de que os profissionais que se formam estejam prontos para encarar as novas demandas e vencer os 
desafios desse mundo contemporâneo, visando a tutela adequada dos direitos e dos indivíduos, com a promoção do bem comum e da pacificação social.

\section{O ESTADO NA SOCIEDADE DA INFORMAÇÃO}

É certo que a sociedade da informação, contemporânea ao século atual, substituiu a sociedade industrial, do século anterior, provocando inúmeras mudanças no cotidiano das pessoas e impactando os diversos setores, como o social, político, econômico, científico, entre outros, com a fomentação e incorporação das inovações tecnológicas cada vez mais presentes.

Com relação a Estado, não foi diferente. Também a concepção de Estado vem sofrendo impactos dessa nova forma de sociedade, representada de forma emblemática pela informação, no conhecimento e nas novas tecnologias, em um contexto de globalização.

A inserção das novas tecnologias da comunicação e informação na sociedade, ocasionada pelo uso e movimentos intensos da informação, sua infra-estrutura e domínio, fragilizam a postura de poder e do exercício do Estado perante a sociedade.

De acordo com Braman (2006), o Estado passa de uma figura reguladora do Estado burocrático ao chamado Estado informacional, da indústria do conhecimento onde as tecnologias da informação e comunicação alteram os materiais, os meios, as regras, as instituições, as idéias e os símbolos estabelecidos anteriormente pela sociedade. Contudo, em um mesmo contexto em que estruturas antigas ainda permanecem, com processos tradicionais, de hierarquias, e atuações.

É por isso que em relação ao Estado, também são verificadas necessárias e paulatinas transformações, a acompanhar esse movimento de evolução e disrupção. E nesse sentido, Lévy (2010) endossa que:

É tendo em mente os novos avanços da emancipação humana que devemos tentar pensar, não 'o fim do Estado', mas 'outro Estado', um que admita plenamente os seus outros, um que emerja da sociedade, embora esteja ao seu serviço, em vez de estar sobranceira a ela, como se transcendência autoritária e burocrática. Podemos apostar que, no futuro, o Estado, que já assumiu tanta forma (teocracia faraônica, império do meio, democracia ateniense, república romana, monarquia europeia, califado, Estado-nação, fascismo, sovietismo, Estado islâmico, federalismo, Estados Unidos, união Europeia...), continuará a metamorfosear-se. (LÉVY, 2010, p. 174-175)

Diante de um novo contexto, portanto, é necessário que também as organizações 
mais tradicionais se reinventem e se adéquem às novas relações e necessidades, passando a desempenhar papéis diversos, a fim de acompanhar e regular as novas maneiras de os mais diversos atores sociais se relacionarem, em âmbito tanto nacional, como internacional.

Assim, há necessidade urgente de desenvolvimento de mecanismos para autoregulação dessas novas formas de relacionamentos que geram efeitos jurídicos nunca antes vivenciados, contexto no qual, conforme acima melhor explanado, emerge o direito informacional.

Dessa maneira, a constatação que se faz é que nesse contexto da sociedade da informação o Estado permanece com preocupações, mantendo importante papel na interferência no âmbito desse novo cenário social.

Observa Kerr Pinheiro (2001, p. 38) que, com o surgimento das tecnologias da informação e comunicação uma nova demanda de políticas de informação passa a ser requisitada. Novas políticas são necessárias para responder às transformações associadas à era da informação e do conhecimento, sua organização, suas novas demandas, aceleração do processo de globalização e a crescente polarização entre pobres e ricos assim como a sustentabilidade do desenvolvimento econômico.

Aos Estados incumbe, então, o dever de implementação de políticas públicas com a finalidade de tratar desse novo objeto que é a informação, a fim de regular e evitar excessos e abusos nessas novas relações.

É possível chegar à conclusão, então, que a informação, o seu trânsito e seus reflexos devem ser objeto de constante preocupação do Estado. E, o papel do Estado nesse contexto pode ser desenhado conforme discorre Maria Eduarda Gonçalves:

Cabe aos Estados, nas sociedades contemporâneas, uma função de ordenação e de regulação das relações sociais e de composição de interesses individuais e sociais, frequentemente no âmbito da prossecução de políticas públicas. No domínio em análise, o direito será condicionado pela política que, de modo explícito ou implícito, o Estado defina para a informação, sua produção e circulação: mais ou menos liberal, tudo dependerá da apreciação dos interesses econômicos e sociais envolvidos e da sua ponderação à luz de princípios da ordem constitucional (GONÇALVES, 2003, p. 24).

Outro ponto que merece destaque ao se analisar o Estado sob a perspectiva contemporânea da sociedade da informação esbarra na concepção da cidadania digital, na 
medida em que a sociedade da informação amplia a possibilidade da participação dos indivíduos nas atividades do Estado.

Nesse sentido, Maria Eduarda Gonçalves observa que:

Os riscos tecnológicos facilitam a politização da vida social e econômica, conduzindo ao questionamento das formas centralizadas e hierarquizadas de exercício do poder típicas da administração público-estatal e à reclamação de processos decisionais mais negociados e participados pelos cidadãos (GONÇALVES, 2003, p. 9).

A sociedade contemporânea fomenta, por meio dos recursos tecnológicos, especialmente daqueles que facilitam a comunicação, maior trânsito das informações, o que confere, por consequência, uma maior participação democrática.

A democracia, por sua vez, está intimamente ligada com a concepção de Estado. E, a partir do momento em que se constata uma maior participação democrática em decorrência do contexto das novas tecnologias estreitando e aproximando as relações entre os indivíduos para além das fronteiras físicas e territoriais, o papel do Estado acaba por sofrer inevitáveis influências dessa nova realidade, necessitando se reinventar para lidar com as novas demandas.

Paulo Hamilton Siqueira Júnior pontua, sobre esse aspecto, que:

O ator principal da democracia ainda é o Estado, mas um Estado também em crise no exercício do seu papel de representante da sociedade. Compreender como as novas ferramentas tecnológicas da sociedade da informação podem estar contribuindo para a ampliação da cidadania, potencializando a democracia, e, também, como os mais diversos canais de informação podem ser utilizados em prol do bem comum, dentro de um Estado Democrático de Direito. Assim, os institutos do direito constitucional no ambiente da sociedade da informação, ganham novo enfoque (SIQUEIRA JÚNIOR, 2007, p. 14).

Outro aspecto que implica em uma nova concepção do Estado sob essa perspectiva contemporânea é que a sociedade da informação, globalizada e pautada pelas inovações tecnológicas e pelos valores do capitalismo cada vez mais dominantes acaba por empoderar cada vez mais os agentes econômicos privados, os quais passam a dominar tarefas antes controladas pelo Estado territorial e soberano.

Com isso, esse capitalismo da sociedade da informação passa a alimentar-se da contradição entre inclusão e exclusão e as redes começam a constituir uma nova morfologia social na teia das interações humanas. Para Siqueira Júnior (2007, p. 15) é assim que o papel 
dos Estados nacionais na definição das direções que deve tomar a pesquisa e a evolução tecnológica torna-se marginal, muito diminuído, sendo o setor privado quem as define.

Dessa maneira, a evolução e o futuro do Estado sob essa perspectiva contemporânea se mostra como um desafio a ser vivenciado, analisado e estudado, com vistas a cuidar de regular as novas relações socioeconômicas de forma a pautar pelo maior equilíbrio entre os atores sociais, combatendo, assim, desigualdades.

\section{CONCLUSÃO}

Diante da análise do tema, constata-se que a sociedade da informação gera severos impactos nos conceitos de Direito e Estado, bem como rompe com toda a sua estrutura tradicional. Assim, as estruturas antigas passam a conviver com as novas demandas e, sob o enfoque desse novo viés, a acompanhar a dinâmica das relações sociais atuais.

Pode-se dizer, em suma, que as inovações tecnológicas e seus reflexos no âmbito da sociedade da informação são analisados positivamente e, também, negativamente, de acordo com diferentes enfoques.

Por um lado, com o advento da sociedade da informação, o desenvolvimento social foi demasiadamente ampliado, permitindo a comunicação de forma rápida e facilitada entre os atores sociais, para além de fronteiras e obstáculos de ordem física, o que propicia maior exercício da cidadania e da participação democrática, bem como garante exercício facilitado de direitos e liberdades.

Por outro lado, como pontos negativos da sociedade da informação, é possível mencionar questões relacionadas às desigualdades sociais. Isso porque, a sociedade da informação, pautada nas novas tecnologias e nos avanços cada vez mais céleres e disruptivos, acaba gerando maior risco de agravamento de desigualdades já existentes, além de criar novas disparidades, a exemplo das próprias condições para o acesso à informação, da violação de garantias de proteção da vida privada e de segurança.

É nesse contexto que o Direito e o Estado necessitam de uma compreensão sob essa perspectiva contemporânea, a fim de que sejam desempenhados os seus papéis de forma acurada, contemplando as demandas atuais e contribuindo para o equilíbrio da expansão socioeconômica e global, mas sem esquecerem de promover o bem estar e o desenvolvimento daqueles indivíduos e setores já marginalizados, para que se insiram na nova realidade. 
Não se pode perder de vista que a evolução tecnológica é constante, sendo que o expoente da sociedade contemporânea informacional se subsume, na realidade, ao aprimoramento do processamento e armazenamento de dados.

Tal cenário passa a exigir dos operadores do Direito que acompanhem as constantes evoluções tecnológicas e se atualizem de acordo com as exigências e demandas oriundas desse novo formato social, baseado em informação e dados, a fim de que compreendam e consigam desenvolver e operar mecanismos adequados para regulação, controle e resolução dos conflitos que se apresentarem.

Isso porque, é crível que os efeitos das novas tecnologias de informação e comunicação sobre as relações sociais passam a criar novos tipos de conflitos, o que vem acompanhado de novas demandas, com a necessidade de adaptação das formas de tutela dos novos conflitos e direitos.

Dessa maneira, o Direito, no contexto da sociedade da informação, passa a exigir uma nova leitura dos diversos institutos jurídicos, bem como leva os seus operadores a refletirem e buscarem uma revisão dos conceitos tradicionais, uma vez que a necessidade passa ser a adequação à nova realidade informacional. E, com isso, pode-se concluir que o Direito se torna cada vez mais complexo.

Então, não se pode negar que a sociedade da informação modificou profundamente as relações sociais, econômicas e de poder no mundo globalizado, afetando, conseqüentemente, o que se compreendia por Direito e por Estado.

Assim, para acompanhar a evolução rápida e contínua da sociedade contemporânea, é imperiosa a revisão de conceitos e paradigmas, inclusive sobre a concepção de que o Direito seria um mero conjunto de regras positivadas pelo Estado.

Diante desse raciocínio, também se vislumbra prementes os impactos sobre as concepções do Estado frente à nova realidade social, já que as fontes estatais do Direito existentes e consolidadas passam a se mostrar, em diversas situações, incapazes de solucionar os conflitos. Isso porque as novas demandas exigem que os operadores do Direito não só o desenvolvimento de novas habilidades, como também que recorram a outras fontes para a pacificação social, inclusive, as não-estatais.

Dessa maneira, tendo em vista essa concepção da sociedade contemporânea, pautada na valorização da informação e que traz consigo pontos positivos e negativos, tanto o Estado, como o Direito, são impulsionados a desenvolverem mecanismos de proteção da informação 
dos dados, sobretudo os pessoais, sendo este tema de intenso debate na atualidade.

Nessa conjuntura, o Direito não se resume ao fato social normativo, incluindo, também, a dinâmica da sociedade. Cada vez mais, as normas e os princípios jurídicos tornamse as bases pertinentes para resolver os casos concretos atuais, de forma que se exige do profissional do Direito uma postura criativa e multidisciplinar, não de mero aplicador da norma positivada.

E, do ponto de vista do Estado, sobretudo com relação ao seu aspecto político e constitucional, a tendência passa a ser de enfraquecimento de seu poder, uma vez que, no contexto de globalização, não é possível mantê-lo como fonte única e exclusiva de Direito, a controlar e regular todos os conflitos e demandas sociais.

Espera-se, portanto, que os operadores do Direito possam acompanhar as evoluções tecnológicas e desenvolver novas competências, de forma a responder, de forma criativa e a contento, às novas demandas sociais. Espera-se, ainda, que o Estado possa manter-se em compasso com o movimento global, acompanhando as diretrizes e tendências de regulamentação e de legitimação, buscando melhor definição da situação jurídica da sociedade da informação, promovendo mecanismos de tutela dos novos bens jurídicos e desenvolvendo políticas públicas para prevenção e diminuição das desigualdades advindas dessa sociedade contemporânea informacional.

\section{REFERÊNCIAS}

ARAUJO, V.M.R.H. de. Sistemas de recuperação da informação: nova abordagem teórico-conceitual. 1994. Tese (Doutorado em Comunicação e Cultura). Rio de Janeiro: Escola de Comunicação da UFRJ, 1994.

CASTELLS, Manuel. A Sociedade em Rede. A era da informação: economia, sociedade e cultura, São Paulo: Paz e Terra, 6 ${ }^{\mathrm{a}}$ ed.Vol 1, 2010.

DUPAS, Gilberto. Ética e poder na Sociedade da Informação. $2^{\mathrm{a}}$ ed. São Paulo: Editora Unesp, 2000. 
DUPAS, Gilberto. Ética e poder na sociedade da informação: revendo o mito do progresso. Rev. Bras. Educ. [online]. 2001, n.18, pp.117-122. http://dx.doi.org/10.1590/S1413-24782001000300011 .

ELIAS, Paulo Sá. Algoritmos, Inteligência Artificial e o Direito, p. 1. Disponível em https://www.conjur.com.br/dl/algoritmos-inteligencia-artificial.pdf, acesso em 03 jan. 2021.

FIORILlO, C. A. P. Princípios Constitucionais do Direito da Sociedade da Informação. São Paulo: Saraiva, 2015.

FREIRE, Rodrigo da Cunha Lima. O processo civil na sociedade da informação: estudo de um caso. Revista dos Instituto dos Advogados de São Paulo 17: 241-260. São Paulo: Revista dos Tribunais, 2006.

GONÇALVES, Maria Eduarda. Direito da informação: novos direitos e formas de regulação na sociedade da informação. Coimbra, Portugal: Almedina, 2003.

KERR PINHEIRO, Marta M. A construção de políticas nacional e supranacional de informação: desafio para os Estados nacionais e blocos regionais. Ciência da Informação, Brasília, v. 28, n. 2, maio./ago. 1999. Disponível em: http://www.scielo.br/pdf/ci/v28n2/28n2a03.pdf

LÉVY, Pierre. Cibercultura. Editora 34, 2010

LISBOA, Roberto Senise. Direito na Sociedade da Informação. Revista dos Tribunais, São Paulo, ano 95, v. 847, 2006.

MASUDA, Yoneji. A Sociedade da Informação como Sociedade Pós-industrial. Rio de Janeiro: Rio, 1980.

MARQUES, Claudia Lima. Confiança no comércio eletrônico e a proteção do consumidor. Um estudo dos negócios jurídicos de consumo no comércio eletrônico. São Paulo: Ed. RT, 2004.

NOVAIS, Paulo; FREITAS, Pedro Miguel. Inteligência Artificial e regulação de algoritmos. Disponível em:

https://www.sectordialogues.org/documentos/proyectos/adjuntos/49f7d3_Intelig\%C3\%AAnci a\%20Artificial\%20e\%20Regula\%C3\%A7\%C3\%A3o\%20de\%20Algoritmos.pdf. Acesso em: 06. jan. 2021.

SIQUEIRA JR., Paulo Hamilton. Direito Informacional: Direito da Sociedade da Informação, Revista dos Tribunais, São Paulo, ano 2007. v. 859, 2007.

SIQUEIRA JR., Paulo Hamilton. Lições de introdução ao direito. 5. ed. São Paulo: Juarez de Oliveira, 2003. 
ZUFFO, João Antonio. A sociedade e a economia no novo milênio: os empregos e as empresas no turbulento alvorecer do século XXI. Livro I: a tecnologia e a infossociedade. Barueri: Manole, 2003 